\title{
Phase Manifestation and Formation of Nanoemulsions Composed of Imidazolium-based Ionic Liquid, Tween 80/Span 80 and Labrafac Lipophile WL 1349
}

\author{
S. H. $\mathrm{NG}^{1 *}$, P. M. WOI ${ }^{2}$ AND C. C. $\mathrm{ENG}^{2}$
}

\begin{abstract}
Ionic liquids (ILs) can enhance topical and transdermal delivery, as well as increase the solubility of sparingly soluble drugs. In the present work, pseudo-ternary phase diagrams of emulsions were composed of a mixture of non-ionic surfactants, polyoxyethylene sorbitan monooleate (Tween $80^{\circledR}$ ) and sorbitan monooleate (Span $80^{\circledR}$ ) in weight fraction: 1:1, 1:2, 2:1 and 2:3, Labrafac ${ }^{\mathrm{TM}}$ Lipophile WL 1349 as an oil phase and 1-hexyl-3-methylimidazolium chloride [(HMIM) (Cl)] as a continuous phase. Emulsion formulations were selected with $10 \%$ surfactants from the pseudo-ternary phase diagrams and further prepared at $298.2 \pm 0.1 \mathrm{~K}$. Acoustic emulsification method was used to prepare nanoemulsions that were mixed with freshly prepared hydrocolloid gum. The area of the single-phase zone in pseudo-ternary phase diagrams that varied with Tween $80^{\circledR} / \mathrm{Span} 80^{\circledR}$ ratio in the order of 2:1>1:1>2:3>1:2 where Span $80^{\circledR}$ was replaced by an equivalent weight of Tween $80^{\circledR}$ to form IL-based nanoemulsions. [HMIM] [Cl] tended to create a two-phase system. Addition of carbopol ${ }^{\circledR}$ ultrez 20 copolymer into the continuous phase of the formulations gave single-phase nanoemulsions with good stability. The mixture of surfactants with weight ratio of 1:2 (Tween $80^{\circledR} /$ Span $80^{\circledR}$ ) showed a good stability with the smallest particle size and greater surface charges in the system. These ionic liquid-based nanoemulsions might have the potential in drug delivery systems.
\end{abstract}

Key words: Ionic liquid; pseudo-ternary phase diagram; Carbopol ${ }^{\circledR}$ ultrez 20 copolymer; particle size

During recent decades, a class of environmentally friendly solvents, ionic liquids (ILs), has received growing interest due to their fascinating and outstanding physicochemical properties. Generally, ionic liquids (ILs) consist of large inorganic anions paired with organic cations and are liquefied salts. Properties of ILs such are low combustibility, wide electrochemical window, excellent thermal stability, wide liquid regions and exhibit low vapor pressure (Eastoe et al., 2005). On account of some of their peculiar properties, ILs can be used as 'green' alternatives to volatile organic solvents for a wide range of applications (Eastoe et al. 2005).

In recent years, ILs has gained several interests for the use in pharmaceutical applications such as solubilization of poorly soluble drugs (Jaitely, Karatas \& Florence 2008; Mizuuchi et al. 2008; Moniruzzaman et al. 2010). IL-based microemulsions has become an interesting topic (Qiu \& Texter 2008) and has advantages such as they can

${ }^{1}$ School of Pharmacy, International Medical University, 57000 IMU Bukit Jalil, Kuala Lumpur, Malaysia

${ }^{2}$ Department of Chemistry, Faculty of Science, University of Malaya, 50603 Kuala Lumpur, Malaysia

* Corresponding author (e-mail: sookhan_ng@imu.edu.my) 
dissolve hydrophilic and hydrophobic chemicals substances and thus widen the use of ILs. On the other hand, ILs also exhibits antimicrobial activity that can make them useful as formulation preservatives or active pharmaceutical ingredients (APIs) (Pernak, Sobaszkiewicz \& Mirska 2003).

ILs have also been studied in classical colloid and surface chemistry because of its amphiphilic nature, and IL-based microemulsions are the most popular (Smirnova et al. 2009; Zech \& Kunz 2011). The first ILbased microemulsion was reported by Gao et al. (2004) where an IL was used to replace water content (Zech et al. 2010). In the subsequent investigations, various kinds of IL-based microemulsions have been prepared (Zech et al. 2010; Harrar et al. 2011; Behera, Dahiya \& Pandey 2007; Zhang et al. 2011; Cheng et al. 2007). In most of the studies on ILbased microemulsions, the IL, such as 1-butyl3-methylimidazolium tetrafluoroborate $\left(\mathrm{C}_{4} \mathrm{mim}\right)$ $\left(\mathrm{BF}_{4}\right)$, was used as a replacement for water (Gao et al. 2007; Gao et al. 2007). Nevertheless, some ILs may serve as an appropriate replacement for oil phase, such as 1-butyl-3-methylimidazolium hexafluorophosphate $\left(\mathrm{C}_{4} \mathrm{mim}\right)\left(\mathrm{PF}_{6}\right)$ (Gao et al. 2006; Behera, Malek \& Pandey 2009). Long alkyl chain ILs can also be used as surfactants, which are named as surface-active ionic liquids (Zech et al. 2009; Govind et al. 2012).

Nanoemulsions are a type of emulsions with uniform, extremely small droplet size, in the range 20-200 $\mathrm{nm}$ (Solans et al. 2003), and are optically transparent. Nanoemulsions have gained several interests for the use in many different applications due to its low viscosity, high kinetic stability against creaming or sedimentation and a large interfacial area (Solans et al. 2003). Nanoemulsions are also known as an isotropic mixture of natural or synthetic oils with surfactants and cosurfactants that form fine oil-in-water $(\mathrm{O} / \mathrm{W})$ or water-in-oil (W/O) with the droplet size usually below $500 \mathrm{~nm}$ (Solans et al. 2003).
The main objectives of this work are construction of pseudo-ternary phase diagrams and fabricate imidazolium-based IL nanoemulsions. In the design of the imidazolium-based IL nanoemulsions, 1-hexyl3-methylimidazolium chloride [(HMIM) (Cl)] was chosen as the hydrophilic IL. The pseudo-ternary IL/Tween $80^{\circledR}$-Span $80^{\circledR} /$ oil system consisted of IL stabilized by a mixture of two nonionic surfactants, polyoxyethylene sorbitan monooleate (Tween $80^{\circledR}$ ) and sorbitan monooleate $\left(\operatorname{Span} 80^{\circledR}\right)$ in Labrafac ${ }^{\mathrm{TM}}$ Lipophile WL 1349. In this study, Tween $80^{\circledR}$ and Span $80^{\circledR}$ surfactants were selected because the mixture of these surfactants offer many advantages over ionic surfactants including increased stability, formulating flexibility and wider compatibility. In addition, Tween $80^{\circledR}$ has hydrophilic PEO groups, which have a strong affinity with the imidazolium cation attached in ILs (Lu \& Rhodes 2000). Dynamic light scattering (DLS) and zeta potential have been used to characterize the nanoemulsion systems.

\section{MATERIALS AND METHODS}

\section{Materials}

The ionic liquid (IL) used was hydrophilic 1-hexyl-3-methylimidazolium chloride [(HMIM) (Cl)] from Sigma-Aldrich Chemical Co. US. Polyoxyethylene sorbitan monooleate (Tween $80^{\circledR}$ ) and sorbitan monooleate $\left(\operatorname{Span} 80^{\circledR}\right.$ ) were used as the hydrophilic and hydrophobic emulsifier, respectively and were purchased from Sigma-Aldrich Chemical Co. US. The oil used was Labrafac ${ }^{\text {TM }}$ Lipophile WL 1349 and was purchased from Gattefosse, France. The thickening agent used was Carbopol ${ }^{\circledR}$ Ultrez 20 copolymer from Lubrizol, USA.

\section{Methods}

Pseudo-ternary Phase Diagrams of the Emulsions. Labrafac ${ }^{\mathrm{TM}}$ Lipophile WL 1349 with surfactants (Tween $80^{\circledR} / \mathrm{Span} 80^{\circledR}$ ) mixture at various weights ranging from 0:100 to 100:0 were weighed. A total weight of $0.5 \mathrm{~g}$ mixture 
was placed in a $10 \mathrm{ml}$ screw-cap glass tube, subjected to vortex for $30 \mathrm{~min}$, and then stored at $298.2 \pm 0.1 \mathrm{~K}$ overnight. An approximately $0.1 \%$ by weight of IL was added to the samples and homogenized for 2 min using a vortex mixer. Next, the samples were centrifuged for $15 \mathrm{~min}$ at $4000 \mathrm{rpm}$. Cross-polarized light was used to visually examine the phase changes of the samples for the determination of anisotropic and isotropic regions. The different phase regions were then classified into isotropic (L), two-phase $(\mathrm{T})$ or three-phase $\left(\mathrm{T}_{1}\right)$. Mixtures of Tween $80^{\circledR}$ and Span $80^{\circledR}$ with the following ratios in weight fraction: 1:1, 1:2, 2:1 and 2:3 were used to study the phase behaviour.

\section{Emulsions Compositions from Pseudo- ternary Phase Diagrams}

Composition of the selected emulsions preparation comprised of $10 \%$ surfactants from the pseudo-ternary phase diagram. The selections of dispersed and continuous phases of the present phase diagrams comprised $30 \%$ (w/w) Labrafac ${ }^{\text {TM }}$ Lipophile WL 1349 and 60\% (w/w) IL, respectively. Carbopol ${ }^{\circledR}$ Ultrez 20 copolymer was added in the continuous phase other than IL as a thickening agent.

\section{Emulsions Preparation}

An emulsion of selected composition from pseudo-ternary phase diagrams was prepared through acoustic emulsification method. A hydrocolloid gum, carbopol ${ }^{\circledR}$ ultrez 20 copolymer, was dispersed in deionized water at $2 \%(\mathrm{w} / \mathrm{w})$ and then stored overnight. Ultrasonicator (UP400S Hielscher Sonifier, Germany) of $400 \mathrm{~W}$ nominal power and a frequency of $24 \mathrm{kHz}$ equipped with a $22 \mathrm{~mm}$ sonotrode tip was used to prepare emulsions. The system was placed in a custom-built cooling jacket where chilled water passed through the jacket continuously at $3^{\circ} \mathrm{C}$. An emulsion sample was prepared and homogenized for 5 min at $6000 \mathrm{rpm}$ with a polytron ${ }^{\circledR}$ homogenizer (Kinematica $\mathrm{GmbH}$, Germany) rotor stator. The sample was then further homogenized using ultrasonic cavitation for $5 \mathrm{~min}$. The sonifier tip horn was adjusted to $3 \mathrm{~cm}$ below the surface of a $100 \mathrm{ml}$ sample. Ultrasonic cavitation was performed at the acoustic amplitude of $20 \%$ and 0.5 cycles. All samples were kept at room temperature, $298.2 \pm 0.1 \mathrm{~K}$.

\section{Particle Size Measurements of the Emulsions}

DLS technique utilizing a Malvern Zetasizer light scattering instrument (Malvern, UK) was used to determine the mean droplet size and size distribution by diluting one drop of the emulsion system with $10 \mathrm{ml}$ of an aqueous phase containing deionized water. After the emulsion samples had been equilibrated for 24 $\mathrm{h}$, the samples were filtered to remove dust or contaminants. Measurements were performed at $\mathrm{T}=298.2 \pm 0.1 \mathrm{~K}$.

\section{Zeta Potential Measurements of the Emulsions}

Zetasizer Nano (Malvern Instruments, UK) was used to perform zeta potential analysis. Zeta potential values either above or below \pm 30 $\mathrm{mV}$ are usually stable emulsions without any coalescence and flocculation of the droplets in the system. Each sample was analyzed thrice, and each analysis consisted of five replicates.

\section{RESULTS AND DISCUSSION}

\section{Pseudo-ternary Phase Diagrams of the Emulsions}

Phase behaviour provides an essential clue to macroscopic behaviour, as it is an important factor in the thermodynamic characterization of the system. In addition, phase behaviour is an intimate way to express molecular or particle or inter-aggregate interactions on a monocular level. The basic principle is to mix the components and observe the number and nature of the phases (Pillai \& Shah 1996). Phase diagrams are shown to provide valuable information on the role played by structures of 
the polar phase, non-polar phase and surfactant in determining the properties of the system at any composition. As usually stated, regions of the emulsion could be characterized by ternary phase diagrams. Here, Tween $80^{\circledR} /$ Span $80^{\circledR}$ were used as the surfactants, and imidazolium IL of 1-hexyl-3-methylimidazolium chloride [(HMIM) (Cl])] and Labrafac ${ }^{\circledR}$ Lipophile WL 1349 were selected as the water and oil phase, respectively.

The transition from turbidity to transparency was observed to determine the phase boundaries. The liquid + liquid equilibrium phase diagrams

(a)

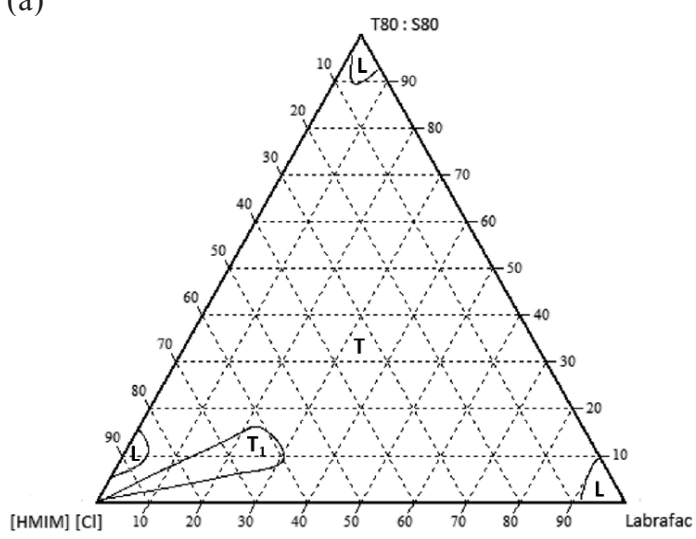

(c)

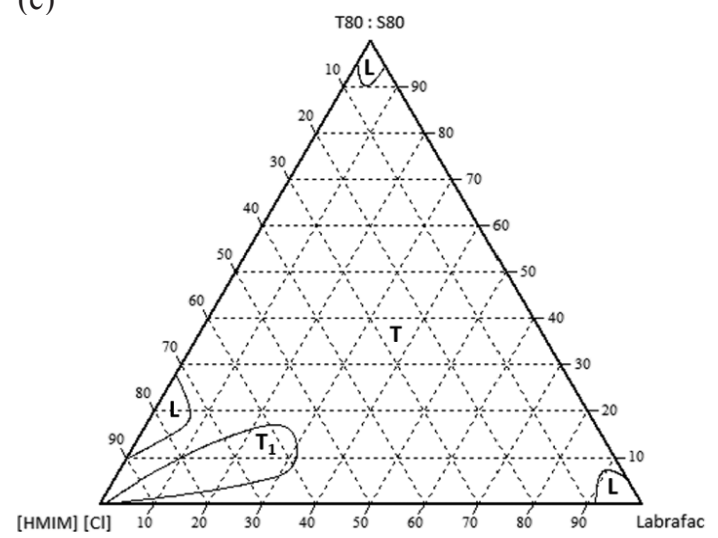

of HMIM Cl/Tween $80^{\circledR}$-Span $80^{\circledR} /$ Labrafac $^{\text {TM }}$ Lipophile WL 1349 at $\mathrm{T}=298.2 \pm 0.1 \mathrm{~K}$ were investigated. Figures 1 (a), (b), (c) and (d), respectively represented the phase diagrams of three-components system with Tween $80^{\circledR} /$ Span $80^{\circledR}$ ratios, $1: 1,1: 2,2: 1$ and $2: 3$. A large amount of IL can be solubilized in the systems with a mixture of two surfactants. Nonionic surfactants in the presence of a second surfactant can dissolve water or oil to form o/w or w/o emulsions (Porras et al. 2008; Kunieda, Nakano \& Akimaru 1995). This is because the second surfactant reduces interfacial tension of the system. (b)

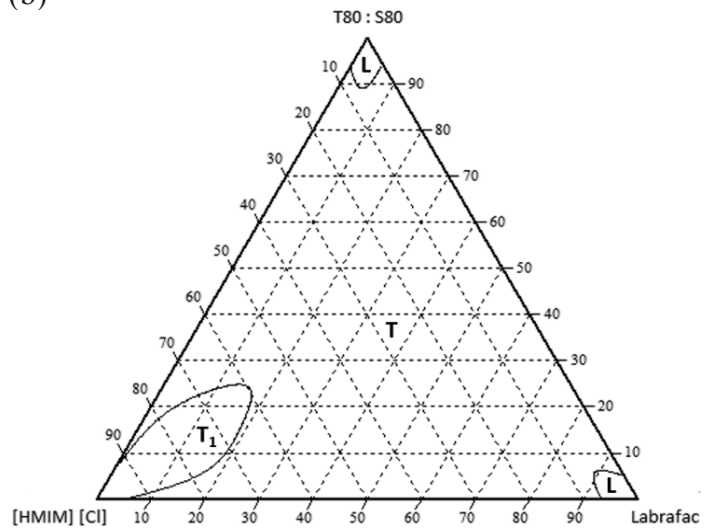

(d)

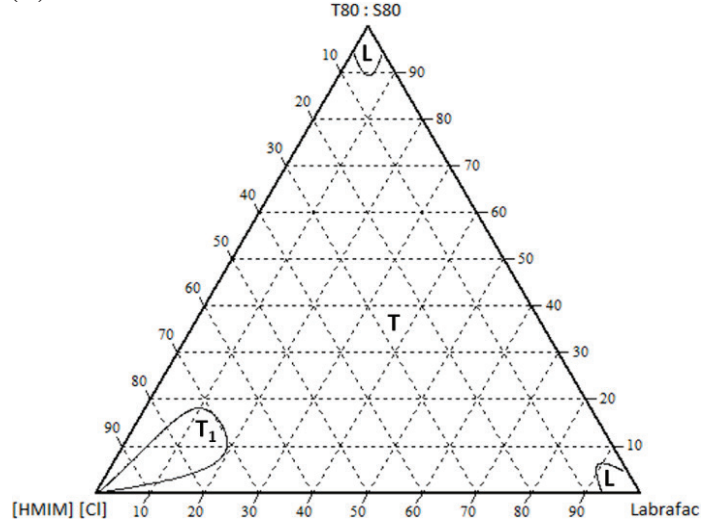

Figure 1. Pseudo-ternary phase diagram of the HMIM Cl/Tween $80^{\circledR}$-Span $80^{\circledR} /$ Labrafac $^{T M}$ Lipophile WL 1349 three component systems at $T=(298.2 \pm 0.1) K$ where $L=$ isotropic region, $T=$ two-phase region, $T_{1}=$ three-phase region. The weight ratio of Tween $80^{\circledR} /$ Span $80^{\circledR}$ (w/w): (a) 1:1; (b) 1:2; (c) $2: 1$ and (d) $2: 3$. 
The phase diagram of HMIM Cl/Tween $80^{\circledR}$-Span 80/Labrafac ${ }^{\mathrm{TM}}$ Lipophile WL 1349 systems is shown in Figure 1. A one-phase region was observed, consisted an isotropic region (L) with the Tween $80^{\circledR} /$ Span $80^{\circledR}$ ratio in the order of $2: 1>1: 1>2: 3>1: 2$, which indicated that the formation of IL-based emulsions where Span $80^{\circledR}$ was replaced by an equivalent weight of Tween $80^{\circledR}$. By comparing the results from previous studies (Gao et al. 2006; Chakrabarty et al. 2005) with the results obtained in Figure 1, a large amount of IL can be solubilized in emulsions using much lower weight fractions of the mixture of Tween $80^{\circledR}$ and Span $80^{\circledR}$ surfactants. These can be explained in terms of interfacial properties provided by the mixtures of two different nonionic surfactants that are more favourable. Isotropic emulsions systems significantly affect the effectiveness as a delivery vehicle and shelf life.

In region $\mathrm{T}$ (two-phase region) and $\mathrm{T}_{1}$ (three-phase region), phase separation occurred in a larger area where phase equilibria were not observed and emulsions were unstable. Two-phase region was dominant at most parts of the compositions that showed instability and incapability of the surfactant to work in emulsifying Labrafac ${ }^{\mathrm{TM}}$ Lipophile WL 1349. Phase separation was observed for most ratios of imidazolium IL, HMIM Cl in emulsions containing less than 5\% Labrafac ${ }^{\mathrm{TM}}$ Lipophile WL 1349, with the sample prepared formed insoluble aggregates that remained at the bottom of the screw-cap glass tube and with a cloudy layer at the top.

\section{Emulsions Compositions from Pseudo- ternary Phase Diagrams}

An emulsion of selected composition from pseudo-ternary phase diagrams comprised of $30 \%(\mathrm{w} / \mathrm{w})$ disperse phase, $10 \%(\mathrm{w} / \mathrm{w})$ surfactants and $60 \%(\mathrm{w} / \mathrm{w})$ continuous phase. Surfactants mixture of $10 \%(\mathrm{w} / \mathrm{w})$ of Tween $80^{\circledR}$ and Span $80^{\circledR}$ with ratios: $1: 1,1: 2,2: 1$ and $2: 3$ were used to avoid or minimize any adverse toxicological or dermatological effect. To determine the stability of the system, hydrocolloid gum, carbopol ${ }^{\circledR}$ ultrex 20 copolymer $[2 \%(\mathrm{w} / \mathrm{w})]$ was added into the continuous phase as a thickening agent. Hydrocolloid gum gave a single-phase with good stability to the emulsions system. Hydrocolloid gum increased the viscosity of the continuous phase that surrounds the oil droplets and therefore restricting the movement of particles. The high droplet concentration enhanced the stability of the emulsions as their movements were blocked by each other (McClements 1999). Thus, this slowed down the creaming rate, followed by the destabilization of emulsion.

\section{Particle Size Measurements}

The sizes and size distribution of colloidal dispersions were characterized by DLS method. A sample was irradiated with a laser beam and the resulting intensity of the scattered light produced by the particles fluctuates at a rate that was dependent upon the particles size. Nonionic surfactant weight ratio varying from $1: 1,1: 2$, 2:1 and 2:3 were studied. A series of samples were chosen from the pseudo-ternary phase diagrams for formulation and further studied using DLS method at different surfactants mixture ratio compositions. Figure 2 shows the particle size distribution plots that appear as S-shaped curve for four emulsions.

From the particle size distribution plots, it showed that the particle sizes with the cumulative distribution of $50 \%$ are the median droplet diameter. Nanoemulsion with weight ratio of Tween $80^{\circledR} / \operatorname{Span} 80^{\circledR}(\mathrm{w} / \mathrm{w})$ of $1: 2$ had a very small distribution with $50 \%$ of the particles under $176 \mathrm{~nm}$ compared to the emulsion with weight ratio of Tween $80^{\circledR} / \mathrm{Span} 80^{\circledR}(\mathrm{w} / \mathrm{w})$ of $2: 3,2: 1$ and $1: 1$, with $50 \%$ of the particles under $191 \mathrm{~nm}, 319 \mathrm{~nm}$ and $550 \mathrm{~nm}$, respectively. The results demonstrated that for the dispersions system containing higher concentration of Span $80^{\circledR}$ with weight ratio of Tween $80^{\circledR} /$ 


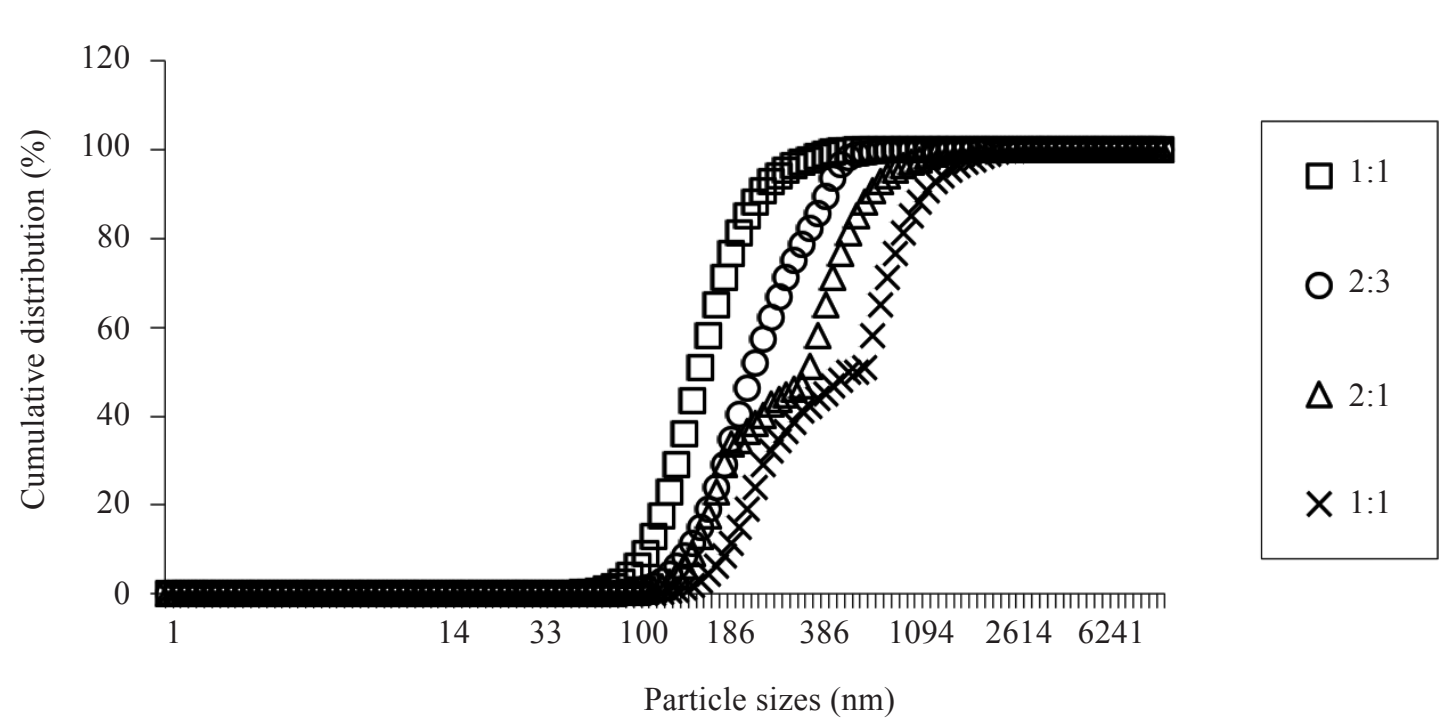

Figure 2. Cumulative particle size distribution at $T=(298.2 \pm 0.1) \mathrm{K}$ of $10 \%(w / w)$ surfactants. The weight ratio of Tween $80^{\circledR} /$ Span $80^{\circledR}(w / w): 1: 2,2: 3,2: 1$ and 1:1.

Span $80^{\circledR}(\mathrm{w} / \mathrm{w})$ of $1: 2$ and $2: 3$, the particle size decreased progressively. This observation can be explained as a result of increasing surfactant adsorption around oil interface of a droplet, and decreasing interfacial tension in the system, which favours the formation of nanoemulsions with smaller particle sizes (Lamaallam et al. 2005). It was observed that for the addition of Tween $80^{\circledR}$ concentration, there was an obvious shift of the plotted curves into the range of larger particle sizes. With higher surfactant concentration of Tween $80^{\circledR}$, the emulsions system leads to larger interfacial areas and consequently resulted in large particle sizes.

An addition of a co-surfactant to the emulsions is well known to alter their parameters. By using a standard practice of two different surfactants, it can develop an emulsion with optimal long-term stability and better steric stabilization of the droplets. Smaller droplet sizes with greater long-term stability can be observed by the addition of imidazolium cations to the formulation that can change the arrangement of the surfactants on the surface of oil droplets (Bataller et al. 2004).

\section{Zeta Potential Measurements}

Figure 3 shows the zeta potential for emulsions at room temperature. Zeta potential for the emulsions was in the range of $-45.70 \mathrm{mV}$ to $-51.60 \mathrm{mV}$ with the addition of carbopol ${ }^{\circledR}$ ultrez 20 copolymer. The surface charges of emulsions with weight ratio of Tween $80^{\circledR} /$ Span $80^{\circledR}(\mathrm{w} / \mathrm{w}), 1: 2,2: 3,2: 1$ and $1: 1$ were $-51.60,-50.10,-48.30$ and $-45.70 \mathrm{mV}$, respectively. Zeta potential that gives a value of greater than or less than $25 \mathrm{mV}$ indicates deflocculated and flocculated emulsions, respectively (Leiberman, Reiger \& Banker 1989). Therefore, no flocculation is observed in all prepared emulsions. The stability of an emulsion can be improved with an increase in the surface charge (Liu et al. 2006).

The distribution of ions in the surrounding interfacial region could be affected by the development of a net charge at the particle surface. An electric double layer around each particle would be formed by increasing the concentration of ions of opposite charge to that of the particle close to the surface. Particles tend to repel each other and there was no 


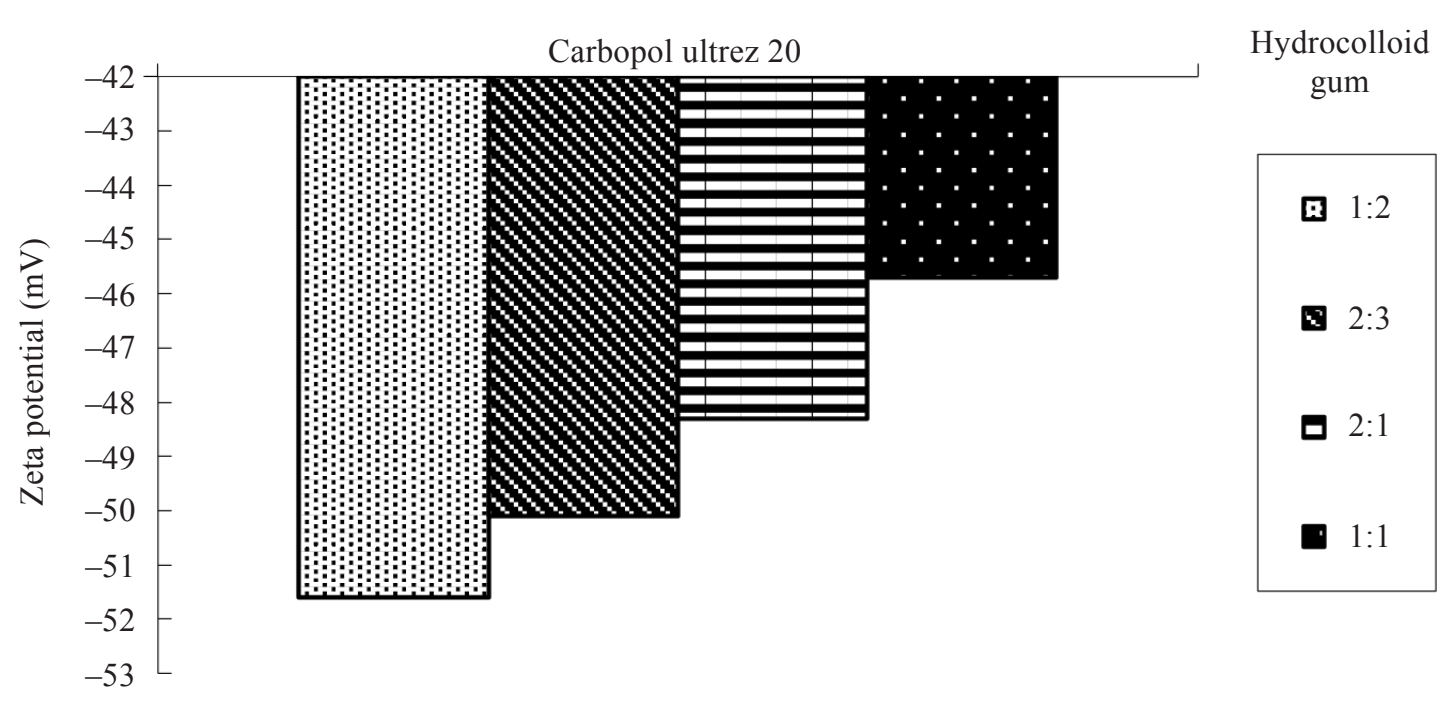

Figure 3. The zeta potential of emulsions at $T=(298.2 \pm 0.1) \mathrm{K}$ of $2 \%(w / w)$ hydrocolloid gum. The weight ratio of Tween $80^{\circledR} /$ Span $80^{\circledR}(w / w): 1: 2,2: 3,2: 1$ and $1: 1$.

observation of flocculation if all the particles had a large negative or positive zeta potential. The negative charged surface is due to the dissociation of acidic groups on the surface of a particle (Kuznesof \& Whitehouse 2005). The imidazolium IL, HMIM Cl, in emulsions contained cations and anions, which have contributed to the negative charge on the surface.

\section{CONCLUSIONS}

The present study indicated that the classic $\mathrm{O} / \mathrm{W}$ emulsions containing hydrophilic imidazolium IL, HMIM Cl were prepared. HMIM Cl was used to replace the water phase and was successfully incorporated into the formulation. DLS was used to estimate the droplet size of selected formulations and exhibited droplet size between the ranges of $176 \mathrm{~nm}$ to $550 \mathrm{~nm}$. Zeta potential for emulsions with carbopol ${ }^{\circledR}$ ultrez 20 copolymer were found between the ranges of $-45.70 \mathrm{mV}$ to -51.60 $\mathrm{mV}$. The increase in hydrophobic emulsifier concentration resulted in the reduced emulsion particle size. IL-based nanoemulsions were successfully formulated by a mixture of nonionic surfactants where strong tendency of the surfactant head groups to bind with IL through the hydrogen bonding with weight ratio of Tween $80^{\circledR} / \operatorname{Span} 80^{\circledR}(\mathrm{w} / \mathrm{w}), 1: 2$ and $2: 3$. ILbased nanoemulsions might have the potential as a drug delivery system.

\section{LIST OF ABBREVIATIONS}

$\mathrm{h}$

HMIM Cl 1-hexyl-3-methylimidazolium chloride

K kelvin

$\mathrm{ml} \quad$ milliliter

$\mathrm{mV} \quad$ millivolt

$\mathrm{nm} \quad$ nanometer

$\mathrm{O} / \mathrm{W} \quad$ oil-in-water

rpm revolutions per minute

w/w weight per weight

\section{ACKNOWLEDGEMENTS}

The present work was supported by the International Medical University and University of Malaya.

Date of submission: September 2015

Date of acceptance: November 2015 


\section{REFERENCES}

Bataller, H, Lamaallam, S, Lachaise, J, Graciaa, A \& Dicharry, C 2004, 'Cutting fluid emulsions produced by dilution of a cutting fluid concentrate containing a cationic/nonionic surfactant mixture', J. Mater Process Technol., vol. 152, pp. 215-220.

Behera, K, Dahiya, P \& Pandey, S 2007, 'Effect of added ionic liquid on aqueous triton X-100 micelles', J. Colloid Interface Sci., vol. 307, pp. 235-245.

Behera, K, Malek, NI \& Pandey, S 2009, 'Visual evidence for formation of water-in-ionic liquid microemulsions', Chem. Phys. Chem., vol. 10, pp. 3204-3208.

Chakrabarty, D, Seth, D, Chakraborty, A \& Sankar, N 2005, 'Dynamics of solvation and rotational relaxation of Coumarin 153 in ionic liquid confined nanometer-sized microemulsions', J. Phys. Chem. B, vol. 109, pp. 5753-5758.

Cheng, S, Zhang, J, Zhang, Z \& Han, B 2007, 'Novel microemulsions: ionic liquid-in-ionic liquid', Chem. Commun., vol. 24, pp. 2497-2499.

Eastoe, J, Gold, S, Rogers, SE, Paul, A, Welton, T, Heenan, RK \& Grillo, I 2005, 'Ionic liquid-in-oil microemulsions', J. Am. Chem. Soc., vol. 127, pp. 7302.

Gao, H, Li, J, Han, B, Chen, W, Zhang, J, Zhang, R \& Yan, D 2004, 'Microemulsions with ionic liquid polar domains', Phys. Chem. Chem. Phys., vol. 6, pp. 2914-2916.

Gao, YA, Li, N, Zheng, LQ, Zhao, XY, Zhang, SH, Han, BX, Hou, WG \&, Li, GZ 2006, 'A cyclic voltammetric technique for the detection of micro-regions of bmimPF / $_{6}$ Tween 20/ $\mathrm{H}_{2} \mathrm{O}$ microemulsions and their performance characterization by UV-Vis spectroscopy', Green. Chem., vol. 8, pp. 43-49.

Gao, YA, Zhang, J, Xu, HY, Zhao, XY, Zheng, LQ, Li, XW \& Yu, L 2006, 'Structural studies of 1-butyl-3-methylimidazolium tetrafluoroborate/ TX-100/ p-xylene ionic liquid microemulsions', Chem. Phys. Chem., vol. 7, pp. 1554.

Gao, Y, Li, N, Zheng, L, Zhao, X, Zhang, J, Cao, Q, Zhao, M, Li, Z \& Zhang, G 2007, 'The effect of water on the microstructure of 1-butyl-3methylimidazolium tetrafluoroborate/TX-100/ benzene ionic liquid microemulsions', Chem. Eur. J., vol. 13, pp. 2661-2670.
Gao, YA, Li, N, Zheng, LQ, Bai, XT, Yu, L, Zhao, XY, Zhang, J, Zhao, MW \& Li, Z 2007, 'Role of solubilized water in the reverse ionic liquid microemulsion of 1-butyl-3-methylimidazolium tetrafluoroborate/TX-100/benzene', J. Phys. Chem. B, vol. 111, pp. 2506-2513.

Govind, RV, Ghosh, S, Ghatak, C, Mandal, S, Brahmachari, U \& Sarkar, N 2012, 'Designing a new strategy for the formation of IL-in-oil microemulsions', J. Phys. Chem. B, vol. 116, pp. 2850-2855.

Harrar, A, Zech, O, Hartl, R, Bauduin, P, Zemb, T \& Kunz, W 2011, '[emim] $\left[\mathrm{etSO}_{4}\right]$ as the polar phase in low-temperature-stable microemulsions', Langmuir, vol. 27, pp. 1635-1642.

Jaitely, V, Karatas, A \& Florence, AT 2008, 'Waterimmiscible room temperature ionic liquids (RTIL) as drug reservoirs for controlled release', Int. J. Pharm., vol. 354, pp. 168-173.

Kunieda, H, Nakano, A \& Akimaru, M 1995, 'The effect of mixing of surfactants on solubilization in a microemulsion system', J. Colloid Interface. Sci., vol. 170, pp. 78-84.

Kuznesof, PM \& Whitehouse, DB 2005, 'Beeswax', in Chemical and Technical Assessment 65th JECFA.

Lamaallam, S, Bataller, H, Dicharry, C \& Lachaise, J 2005, 'Formation and stability of miniemulsions produced by dispersion of water/oil/surfactants concentrates in a large amount of water', Colloid. Surf. A, Physicochem. Eng. Asp., vol. 270, pp. 44-51.

Leiberman, HA, Reiger, MM \& Banker, GS 1989, Pharmaceutical dosage forms: disperse systems, Mercel Dekker, NY.

Liu, W, Sun, P, Li, C \& Liu, Q, Xu, J 2006, 'Formation and stability of paraffin oil-in-water nano-emulsions prepared by the emulsion inversion point method', J. Colloid. Interface Sci., vol. 303, pp. 557-563.

Lu, D \& Rhodes, DG 2000, 'Mixed composition films of Spans and Tween $80^{\circledR}$ at the air-water interface', Langmuir, vol. 16, pp. 8107-8112.

McClements, DJ 1999, Emulsion rheology in food emulsion: principles, practice and techniques, Boca Raton, CRC Press, FL.

Mizuuchi, H, Jaitely, V, Murdan, S \& Florence, AT 2008, Room temperature ionic liquids and their 
mixtures: potential pharmaceutical solvents', Eur. J. Pharm. Sci., vol. 33, pp. 326-331.

Moniruzzaman, M, Tamura, M, Tahara, Y, Kamiya, N \& Goto, M 2010, 'Ionic liquid-in-oil microemulsion as a potential carrier of sparingly soluble drug: characterization and cytotoxicity evaluation', Int. J. Pharm., vol. 400, pp. 243-250.

Pernak, J, Sobaszkiewicz, K \& Mirska, I 2003, 'Anti-microbial activities of ionic liquids', Green Chem., vol. 5, pp. 52-56.

Pillai, V \& Shah, DO 1996, Dynamic properties of interfaces and association structures, AOCS Press, Illinois. 38-43.

Porras, M, Solans, C, Gonzalez, C \& Gutierrez, JM 2008, 'Properties of water-in-oil (W/O) nano-emulsions prepared by low-energy emulsification method', Colloids Surf. A, vol. 324, pp. 181-188.

Qiu, Z \& Texter, J 2008, 'Ionic liquids in microemulsions', Curr. Opin. Colloid Interface Sci., vol. 13, pp. 252.

Smirnova, NA, Vanin, AA, Safonova, EA, Pukinsky, IB, Anufrikov, YA \& Makarov, AL 2009, 'Selfassembly in aqueous solutions of imidazolium ionic liquids and their mixtures with an anionic surfactant', J. Colloid Interface Sci., vol. 336, pp. 793-802.

Solans, C, Esquena, J, Forgiarini, AM, Morales, D, Izquierdo, P, Azemar, N \& Garcia-Celma, MJ 2003, 'Nanoemulsions: formation, properties and applications', Surfactant Science Series, vol. 109, pp. 525-554.

Zech, D, Thomaier, S, Bauduin, P, Ruck, T, Touraud, D \& Kunz, W 2009, 'Microemulsions with an ionic liquid surfactant and room temperature ionic liquids as polar pseudo-phase', J. Phys. Chem. B, vol. 113, pp. 465-473.

Zech, O, Thomaier, S, Kolodziejskl, A, Touraud, D, Grillo, I \& Kunz, W 2010, 'Ionic liquids in microemulsions - a concept to extend the conventional thermal stability range of microemulsions', Chem. Eur. J., vol. 16, pp. 783-786.

Zech, O \& Kunz, W 2011, 'Conditions for and characteristics of non-aqueous micellar solutions and micro-emulsions with ionic liquids', Soft Matter, vol. 7, pp. 5507-5513.

Zhang, J, Han, B, Li, J, Zhao, Y \& Yang, G 2011, 'Carbon dioxide in ionic liquid microemulsions', Angew Chem. Int. Ed., vol. 50, pp. 9911-9915. 